party are Frank M. Setzler, head curator, Department of Anthropology; Dr. David H. Johnson, associate curator, Division of Mammals ; Herbert G. Deignan, associate curator, Division of Birds ; and Dr. Robert R. Miller, associate curator, Division of Fishes, all of the Smithsonian Institution; and Harrison Howell Walker, National Geographic staff writer-photographer with several years of Australian experience. A similar group of Australian scientific workers will take part in the expedition.

\section{Fuel Systems for the Aero-Gas Turbine}

DR. E. A. WATSON and his colleagues were associated with Air Commodore Whittle in the early development of the aero-gas turbine. A paper presented before the Institution of Mechanical Engineers on December 5 gives an account of the results of their researches into fuel systems for such turbines. In the first part of the paper, Dr. Watson deals with the methods used for ensuring that the correct quantity of fuel is supplied to the engine under all conditions of thrust and altitude. The desirable characteristics of fuel systems from this point of view are deduced in a logical way, commencing with a typical heat input-engine speed curve at given inlet pressure and temperature, which is then modified to take into account variation of inlet con. ditions. It is then shown that neither an approximately isochronous governor nor a constant-stroke fuel pump driven directly by the engine possesses the required characteristics. The remaining alternative is to define the fuel flow directly by the pilot's control, with a compensating device for attitude variation. The remainder of this part of the paper is devoted to a discussion of the methods employed to achieve this, illustrated by descriptions of the various devices which have been used.

In the second part of the paper, the author turns his attention to the atomization of the fuel in the burners, and gives an account of some very ingenious methods which have been developed by various investigators to determine particle size and distribution. Illustrations are given of some atomizers which have been used. The paper should be of general interest to all who have followed the development of the gas turbine from its early stages, and the second part of particular interest to those concerned with the combustion of liquid fuels.

\section{The Electronic Organ}

So far as can be ascertained, there is only one type of electronic organ, that is one operating from purely electric means (see Nature, 145, 170 (1940)) and so obviating pipes, being developed and manufactured in Great Britain, namely, the Electrone of the John Compton Organ Co., Ltd. The fact that it is produced by a long-established pipe-organ company means that it is properly 'voiced' by experienced craftsmen, without which it might be feared that traditional organ-t one might be lost. The model now available has two manuals and pedals, and a good array of stops and couplers. It was described by its inventor and designer, Mr. L. E. A. Bourne, and fully demonstrated by Mr. J. I. Taylor at a meeting of the Institution of Electronics held at the Royal Society of Arts on January 26. The post-war model is a great improvement over that produced in small quantities before the War, and can now easily take a place with regular pipe-organs of three times the price and greatly diminished maintenance. The improvement is largely due to a re-design of the electrostatic runners, using formants in many of the tracks instead of the previous all-sine-wave tracks, and more carefully selected loudspeakers. There are twelve unit-generators, all equal but driven by one belt, coupling pulleys of diameters inversely proportional to the equal-tempered ratios. Harmonics up to the thirtieth are used at present, but experiments are being made to go much higher when larger instruments are constructed, that is, larger in the sense of diversity of registration and effects, not volume, since this merely means using more amplifiers and suitably disposed loudspeakers.

\section{Intensive Vegetable Cultivation}

THE increased demand for fresh vegetables has stimulated the grower's interest in new or improved methods of intensive cultivation. There remains, however, the difficulty of providing him with the latest information in an accessible form, and three illustrated bulletins issued by the Ministry of Agriculture (London : H.M. Stationery Office) on different aspects of the subject will do much to meet this need. "Irrigation" (Bull. No. 138. 1s. 6d. net) is entirely new. In it natural water supplies of all types are discussed, and the various methods of augmenting them by means of spray or soil irrigation described. Such artificial systems inevitably entail heavy expenditure, but it is considered that in some circum. stances the results may fully justify it. "Crop Production in Frames and Cloches" (Bull. No. 65. $2 s .6 d$. net) has been completely rewritten. It provides a wealth of practical information, though stressing the fact that a thorough understanding of soils, varieties, ventilation, etc., is needed before success in this specialized line can be expected. "Practical Soil Sterilization" (Bull. No. 22. 1s. 3d. net) appears in a revised form. Large-scale methods employing both steam and chemicals are described for use in glasshouses, but instructions for dealing with small quantities of soil needed for propagation purposes or growing plants in pots are also included.

\section{Annular Eclipse of the Sun on May 8-9}

The National Research Council of Japan has arranged a programme of observations of the ionosphere during the annular eclipse of May 9 next, the central line of which passes across a small island north-west of Hokkaido. One of the objects of the programme is to obtain further evidence on the speed of particles proceeding from the sun to the earth. The exact times of contacts are to be recorded in connexion with a large-scale programme of geophysical observations.

\section{National Foundation for Scientific Research, Brussels}

THE nineteenth annual report of the National Foundation for Scientific Research, Brussels, covering the year 1945-46, includes the reports of the ten scientific commissions together with details of grants made, of distinctions obtained during the academic year, and particulars of researches in progress during 1946-47. A list of publications during the year is appended under authors, together with a classified list of authors according to the scientific commission with which their work is associated. The Commission for Mathematics and Astronomy reports on a study of irregular algebraic surfaces and on correspondences between two algebraic surfaces. Prof. M. A. Picard reports on behalf of the Commission for Physical Chemistry, Electro-chemistry and Radioactivity on 
research on new radioactive substances, while on behalf of the Commission for Morphological Medical Sciences, Prof. M. G. Leplat refers to a study of senescence. The Scientific Commission for Pathology of Transmissible Diseases, Colonial Pathology and Hygiene has studied the extension of bilharziasis and its control, rickettsiosis and filariasis, while the Commission for Clinical Sciences has been investigating the problems of antibiotics and the mode of action of sulphonamides. The Commission for Applied Chemistry has investigated the constitution and chemical properties of mineral oils, and a new Scientific Commission has been set up for the study of problems of nuclear energy.

\section{National Institute of Sciences of India : Elections}

Ar the annual general meeting of the National Institute of Sciences of India, held at Patna on January 1, the following new fellows were elected: Dr. B. S. Bhimachar, fisheries officer with the Government of Mysore, Bangalore; Pratap Chandra Bose, chief engineer, Corporation of Calcutta ; Dr. Satya Charan Chatterjee, head of the Department of Geography, Patna College, Bankipur, Patna; Jehangir Fardunji Dastur, head of the Division of Mycology, Indian Agricultural Research Institute, New Delhi; Dr. Arun Kumar Dutta, reader in physics, Dacea University; Dr. Rukmini Kishore Dutta Roy, Geological Survey of India, Calcutta; Dr. Robert E. Heilig, chief physician, Jaipur; Dr. Kolar Ramakrishna Krishnawami, director of industries, Bihar, Patna; R. A. MacGregor, formerly chief metallurgist to the Government of India, Calcutta; Ganesh Chandra Mitter, chief assayer, His Majesty's Mint, Bombay, and honorary professor of industrial chemistry, Royal Institute of Science, Bombay ; Dr. Mahadeo Atmaram Moghe, professor of zoology, College of Science, Nagpur, and head of the Department of Zoology and dean of the Faculty of Science, Nagpur University; Dr. S. P. Raju, director of the Engineering Research Department, H.E.H. Nizam's Government, Hyderabad, Deccan; Dr. Srinivasa Ramanujam, Central Potato Research Institute, New Delhi; Dr. Subbarao Ramachandra Rao, professor of physics, Central College, Bangalore; Dr. Jyotis Chandra Ray, director, Indian Institute for Medical Research, Calcutta.

\section{Physiology and Pathology of Animal Reproduction}

THE First International Congress on the Physiology and Pathology of Animal Reproduction and on Artificial Insemination will be held during June 23-30 at Milan. On June 21 a preliminary conference will take place, under the auspices of the United Nations Educational, Scientific and Cultural Organisation, at which a limited number of Italian and foreign specialists will discuss "Interacting Substances of Ova and Sperm, and Parthenogenesis". The Scientific Commission of the Congress will arrange the papers sent to the Congress in sections according to subject; full sessions will discuss certain themes of general interest. The subjects the Congress is to deal with are : (a) biological problems of animal reproduction ; (b) breeding problems of animal reproduction; (c) pathological problems of animal reproduction; (d) methodological and practical problems of artificial insemination of animals ; $(e)$ legislative and organisational problems of artificial insemination and of animal reproduction. An exhibition of related material and books, and also visits to breeding stations and scientific institutions, are being arranged. Papers for the Congress must be received by March 31. Detailed information can be obtained from Prof. T. Bonadonna, secretary-general of the Congress (via Bronzetti 17, Milan). The subscriptions are: for mombers actually taking part in the Congress, 8 dollars or $£ 2$; for others, 4 dollars or $£ 1$.

\section{International Symposium on Noise}

An international symposium on noise is to be held by the Acoustics Group of the Physical Society in association with the Royal Institute of British Architects during July 14-16, in the hall of the Institute at Portland Place, London, W.1. The draft programme provides for four sections: (1) noise measurement; (2) field and laboratory studies; (3) reduction of noise, air-borne and structure-borne; (4) building practice, as applied in houses and flats, factories, theatres, concert halls, etc. Contributions to the symposium are invited, and those who intend to read papers or submit written contributions are asked to inform the recorder, Dr. A. J. King, not later than March 31. Anyone wishing to have accommodation reserved should apply as soon as possible to the Accommodation Officer. The address for him and the Recorder of the Symposium is : Acoustics Group, Physical Society, I Lowther Gardens, Prince Consort Road, London, S.W.7.

\section{Royal Meteorological Society}

THE following have been elected officers of the Royal Meteorological Society President, Dr. G. M. B. Dobson; Vice-Presidents, Capt. L. G. Garbett, E. Gold, G. Manley, J. F. Shipley, A. Thomson (for Canada) and J. Paton (for Scotland); Treasurer, W. N. Witehell ; Secretaries, E. L. Hawke and Wing-Comdr. R. M. Poulter; Scottish Secretary, A. J. Drummond; Foreign Secretary, L. C. W. Bonacina ; Councillors, A. C. Best, A. W. Brewer, J. S. Forrest, Major H. C. Gunton, W. G. Kendrew, I. T. D. Kirkpatrick, Dr. A. R. Meetham, Dr. F. J. Scrase, Prof. P. A. Sheppard, A. E. Slater, Lieut.Comdr. P. C. Spink and Dr. T. W. Wormell.

\section{Ethics and Science Conference}

THE Ethics and Science Conference arranged by the British Social Hygiene Council will be held on Friday, March 19, at the Livingstone Hall, London, S.W.1. The main theme of the Conference will be "Society and the Individual", each of the two sessions being devoted to a different aspect of this problem; the speakers at the morning session considering "The Value Society Sets upon the Individual", and at the afternoon session "The Values the Individual Sets before Himself". The chair will be taken by Mr. L. J. F. Brimble and Dr. E. B. Strauss, and the speakers will include Mr. F. Ian G. Rawlins, Canon Marcus Knight, Mr. Kenneth Walker, Dr. E. H. Larkin, Mr. John Mackay-Mure, Mrs. Joan B. Thompson, Father Leycester King, Dr. Mary Smith, and others. Time will be allowed for discussion at both the morning and afternoon sessions and at an open meeting in the evening. It is hoped that, as a result, fresh light will be thrown upon the problems arising from the apparent conflict between the scientific and spiritual interpretations of life. Further information and tickets (members of the Council, 2s. 6d.; others, 3s. 6d.) may be obtained from the British Social Hygiene Council, Dept. S.J.1, Tavistock House North, Tavistock Square, London, W.C.1. 